\title{
AS POLÍTICAS DE PAGAMENTO POR SERVIÇOS AMBIENTAIS DIRECIONADOS À AGROECOLOGIA: DA EMERGÊNCIA DA EXPERIÊNCIA EUROPEIA E DA INEXISTÊNCIA DE MECANISMOS NO BRASIL.
}

\section{RESUMO}

Felipe Franz Wienke ${ }^{1}$

A produção agrícola brasileira é caracterizada pela adoção de práticas pouco sustentáveis, sendo perceptível a carência de instrumentos político-jurídicos aptos a promover uma alteração nas bases produtivas. As experiências de programas de pagamento por serviços ambientais têm alcançado repercussão no direito ambiental, apresentando um potencial significativo para uma transição agroecológica. A Política Agrícola Comum - PAC europeia fornece subsídios para a formulação de um programa de pagamento por serviços ambientais destinado a impulsionar a transição agroecológica no contexto brasileiro, objetivo já consolidado no âmbito das políticas públicas, porém com resultados ainda modestos.

Palavras-chaves: Agroecologia - Pagamento por Serviços Ambietais - Política Agrícola Comum - Transição Agroecológica - Políticas Públicas Ambientais.

\section{THE PAYMENT FOR ENVIRONMENTAL SERVICES (PES) PROGRAMS ADDRESSED TO AGROECOLOGY: THE EMERGENCY OF EUROPEAN EXPERIENCE AND THE ABSENCE OF MECHANISMS IN BRAZIL.}

\begin{abstract}
The Brazilian agricultural production is characterized by the adoption of unsustainable practices. The lack of political-legal instruments capable to promote a change in the productive bases is noticeable.The experiences of Payment for Environmental Services (PES) programs have reached repercussions on environmental law, presenting a significant potential for an agroecological transition.

The Common Agricultural Policy (CAP) provides subsidies for the formulation of a Payment for Environmental Services (PES) program to promote the agroecological transition in the Brazilian context, an objective already consolidated in the scope of public policies, but with still modest results.
\end{abstract}

Keywords : Agroecology - Payment for Environmental Services - Common Agricultural Policy - Agroecological Transition - Environmental Public Policies

\footnotetext{
${ }^{1}$ Doutor em Direito pela Universidade Federal do Rio Grande do Sul - UFRGS, Rio Grande do SUL, (Brasil). Professor colaborador do Programa de Mestrado em Direito e Justiça Social/FURG. Pós-doutorando em Direito/FURG. Universidade Federal do Rio Grande. E-mail: felipefw@gmail.com
} 


\section{INTRODUÇÃO}

O modelo agrícola brasileiro é caracterizado pelo uso excessivo de agrotóxicos e de sementes geneticamente modificadas. Segundo dados do Serviço Internacional para Aquisição de Aplicações em Agrobiotecnologia (ISAAA, 2014, p. 3), o Brasil ocupa a segunda posição no ranking mundial dos países que mais utilizam sementes transgênicas. Em sentido semelhante, o Brasil se apresenta na primeira colocação no que se refere à utilização mundial de agrotóxicos (ABRASCO, 2015, p. 452). As poucas estratégias brasileiras para alterar esse quadro não têm atingido resultados significativos.

Algumas inovações no âmbito do direito ambiental são observadas com potencial para reformar esse quadro. As políticas de pagamento por serviços ambientais, a partir de experiências regionais, têm obtido significativo êxito nas tentativas de recuperação de matas ciliares, florestas nativas e áreas de mananciais, fato que já recebe significativa atenção da doutrina jurídica ambiental ${ }^{2}$. Tais programas parecem se adequar à problemática da produção agrícola, constituindo-se uma importante ferramenta jurídico-política para a mudança no modelo de produção agrícola predominante no país, caracterizado por uma forte preocupação econômica e um restrito enfoque socioambiental.

O presente artigo busca analisar o potencial dos programas PSA como ferramenta para a efetivação da transição agroecológica, conceito este recentemente incorporado ao direito brasileiro. Para tanto, o trabalho propõe inicialmente um estudo conceitual sobre as políticas de pagamento por serviços ambientais (1.1), bem como sobre a noção de transição agroecológica incorporada pelo direito brasileiro (1.2). No segundo momento, o trabalho aborda os programas PSA direcionados à produção agrícola. Primeiramente, a partir do foco na experiência européia, onde a Política Agrícola Comum (PAC) aglutinou a preocupação com a produção de alimentos e com a proteção da biodiversidade (2.1). Posteriormente, com foco no cenário brasileiro, são averiguadas as iniciativas normativas observadas nos últimos $\operatorname{anos}(2.2)$.

\section{A Noção de Pagamento por Serviços Ambientais e de Transição Agroecológica: Um Enfoque Conceitual.}

A noção de pagamento por serviços ambientais - PSA tem ganhado significativa repercussão no direito brasileiro,sobretudo após a promulgação da lei $n^{0}$ 12.651/2012. Contudo, o ordenamento jurídico brasileiro ainda não precisa um conceito de tal instituto, o

\footnotetext{
${ }^{2}$ Nesse sentido, exemplificadamente, vide as obras organizadas por Haide Maria Hupffer, João Alcione Sganderia Figueiredo e José Galizia Tundisi (Pagamento por Serviços Ambientais. Incentivos Econômicos para a Proteção dos Recursos Hídricos e Restauração da Mata Ciliar) e Antônio Hermann Benjamin, Carlos Teodoro Irigaray, ElodioLecey e Silvia Cappeti (Florestas, Mudanças Climáticas e Serviços Ecológicos) - referências completas ao final.
} 
que já é observado, diferentemente, no âmbito doutrinário (1.1). Tais programas, ao propor incentivos econômicos para a promoção dos serviços ambientais, guardam potencial como ferramenta para a efetivação da transição agroecológica, conceito recentemente positivado no Brasil, mas que ainda carece de uma análise jurídica contundente (1.2).

\subsection{O Instituto do Pagamento por Serviços Ambientais}

Embora as políticas PSA tenham se difundido no cenário nacional, sobretudo a partir de experiência regionais, tanto com capital público como privado, é o novo Código Florestal (lei 12.651/2012) que, em seu artigo 41, traz para o direito positivo a possibilidade de instituição de um programa nacional dessa natureza para beneficiar as atividades de conservação e melhoria dos ecossistemas. Antes de adentrar nas peculiaridades trazidas pela lei, uma análise conceitual mostra-se aqui pertinente.

No âmbito acadêmico internacional, a definição do pagamento por serviços ambientais de maior repercussão é aquela trazida SvenWunder, o qual elenca cinco elementos que compõe o conceito, quais sejam: (a) a existência de uma transação voluntária; (b) de um serviço ambiental bem definido ou de uma forma de uso da terra que possa assegurar este serviço; (c) a existência de um comprador; (d) a existência de um provedor e (e) a garantia de que o provedor forneça os serviços (WUNDER, 2005, p. 3).

A descrição acima especificada, porém, parece não abarcar a multiplicidade de situações fáticas observadas no contexto socioambiental, sobretudo quando é desafiada a problemática das terras indígenas, das reservas extrativistas e de outras situações onde a produção dos serviços ambientais se dá coletivamente. Do mesmo modo, o conceito parece ser tímido para responder as complexidades dos serviços ambientais imateriais, os quais não podem ser facilmente medidos e quantificados.

$\mathrm{Na}$ doutrina brasileira, as definições buscam, sobretudo,destacar o papel dos serviços ambientais como externalidades positivas tanto para o homem, como para o próprio meio ambiente. Nessa linha, cabe salientar o conceito de Alexandre Altmann e Alindo Butzke segundo os quaiso pagamento por serviços ambientais constitui a estratégia de conservação da natureza baseada na percepção do valor dos serviços ambientais para o bem-estar humano. Nesta perspectiva, é possível internalizar ao sistema produtivo as externalidades 
ambientais positivas, identificadas como serviços ambientais (ALTAMANN, BUTZKE, 2010, p. 427).

O objetivo do instrumento, nos termos de Susan Seehusen e Ingrid Prem, é recompensar aqueles que produzem ou mantêm os serviços ambientais, bem como incentivar outros a garantirem provimento destes serviços, o que não seria feito sem estes incentivos. Busca-se mudar a estrutura de incentivos de forma a melhorar a rentabilidade relativa das atividades de proteção e uso sustentável de recursos naturais em comparação com atividades não desejadas(SEEHUSEN, PREM, 2011, p. 34).

No mesmo sentido expõe Carlos Teodoro José Irigaray, para quem os programas de pagamento por serviços ambientais se consolidam como alternativa para corrigir as falhas de mercado decorrentes da não valoração econômica dos serviços ambientais. Nos termos do mesmo autor, é fato que o mercado não consegue assimilar, no sistema de preços, os custos integrais dos bens e serviços, fato que implica na implícita concessão de subsídios às atividades poluidoras (IRIGARAY, 2010, p. 15). Alguns aspectos histórico-jurídicos auxiliam a compreensão desse processo.

A constituição do direito de propriedade no contexto pós-revolucionário francês criou um regime de soberania privada para todas as coisas passíveis de apropriação. A Declaração dos Direitos do Homem e do Cidadão de 1793, em seus artigos 16 e 17, consagrou uma concepção de propriedade que é associada definitivamente à liberdade econômica. François Ost salienta que o direito de propriedade tem aversão ao vazio. Todo o trabalho do Código Civil francês consistirá em classificar os elementos da natureza, fazendo deles objeto de apropriação da forma mais exclusiva e total possível.

O mesmo se passa com o direito dos modernos; tendo, a partir de agora, "ocupado" o espaço natural, estes não descansarão enquanto não o revestirem por completo com o manto concretizador da propriedade: também aqui se reencontram as duas características da integralidade (nada escapa à apropriação) e da divisibilidade ilimitada. (...)

O direito de propriedade, é evidente, tem vocação de cobrir todo o espaço disponível. É muito significativo constatar, igualmente, que a lógica individualista de apropriação privada responde, no plano do direito público, um movimento paralelo de ocupação dos espaços ainda disponíveis, sobre o qual se estabelece, então, o reino da soberania estatal (OST, 1995, p. 67-70). 
Nesta linha, todas as coisas que não são passíveis de apropriação direta são colocadas num plano de direito público. Tais bens, por não se enquadrarem na definição de propriedade privada, não possuem valor de mercado e, consequentemente, passam a ser de livre acesso aos particulares (ABDELMALKI, MUNDLER, 2010).

Em linhas gerais, ressalvados recentes avanços, como a cobrança pela outorga de direito de uso da água no Brasil, a utilização de recursos naturais não privados não influi a formação dos preços. Deste modo, as atividades poluentes que acarretam externalidades negativas $^{3}$ não são absorvidas pela racionalidade do mercado. Tal lógica cria um cenário comumente denominado de privatização dos benefícios e socialização dos prejuízos (o que vai constituir a base do princípio do poluidor-pagador). Isso porque, na prática, o poluidor toma para si todo o lucro de sua atividade degradadora, mas compartilha com toda a coletividade os males causados por sua ação poluidora (MORATO LEITE, PILATI, 2006, p. 48). Alexandra Aragão demonstra esta sistemática, com a ideia de custo zero na utilização dos bens ambientais coletivos:

\begin{abstract}
A denominação efeitos externos ao mercado é compreensível, porque se trata de transferência de bens ou prestação de serviços fora dos mecanismos do mercado. São transferências por meios não econômicos na medida em que não lhes corresponde qualquer fluxo contrário de dinheiro. Sendo transferências a preço zero, o preço final dos produtos não as reflete, e por isso não pesam nas decisões de produção ou consumo apesar de representarem verdadeiros custos ou benefícios sociais decorrentes da utilização privada dos recursos comuns (ARAGÃO, 2014, p. 33).
\end{abstract}

Nessa esteira, a noção de externalidade negativa desafia um conceito que trabalha de forma semelhante, mas na lógica oposta, qual seja, o conceito de externalidade positiva (traduzida para o direito ambiental através da noção de serviços ambientais). A internalização de tais serviços em favor de seu fornecedor, por sua vez, constitui a base do princípio do provedor-recebedor. Esse princípio busca efetivar a justiça econômica ambiental e o desenvolvimento sustentável. Nesta linha, ele

\footnotetext{
${ }^{3}$ Importante salientar que a noção de externalidade negativa, antes de constituir um conceito das ciências naturais, é um conceito de teoria econômica, que surge a partir da escola neoclássica. Elas ocorrem quando as ações de algum indivíduo ou empresa impõe custos a outro indivíduo ou empresa (...) Quando ocorrem externalidades negativas, o custo marginal social é maior que o custo marginal privado (MEIRELLES, 2010, p. $650)$.
} 
pode ser encarado como o inverso do princípio do poluidor-pagador, na medida em que proporciona uma justa compensação a todos aqueles que contribuem para a conservação ambiental com suas condutas, ou seja, reconhece as externalidades positivas daqueles cujo comportamento ambiental reduz os gastos públicos e traz benefícios para toda a coletividade (FURLAN, 2010, p. 211).

No contexto da produção agrícola, o pagamento por serviços ambientais se apresenta como uma ferramenta significativa para a promoção da transição agroecológica, buscando, a partir de instrumentos econômicos, atingir modelos produtivos mais sustentáveis.

\subsection{O Instituto da Transição Agroecológica}

Como exposto, o presente trabalho busca abordar o potencial dos programas de pagamento por serviços ambientais como instrumento jurídico-econômico para a transição agroecológica. Nessa linha, cabe investigar os contornos dessa transição, salientando-se a multidimensionalidade do conceito.

A noção de transição mostra-se, por si só, instigante. A transição, como salienta Pascal Chabot, é a mudança desejada. Elas se distinguem das mudanças ordinárias pelo investimento mental e afetivo que as circunda. A transição se opõe à estabilidade e se faz presente cada vez que o futuro se convida nos debates e pesa sobre nossas escolhas (CHABOT, 2015, p. 17 - tradução do autor). Segundo o autor, a transição habita as bordas do sistema. Sejam eles cidadãos, ativistas, intelectuais ou artistas, eles vivem na fronteira entre o presente e o futuro e, de lá, observam a realidade da época desorientada (Ibid., p. 27 tradução do autor). Este movimento não é casual, mas reflexivo. A transição é a mudança a qual se adiciona o pensamento. Ele aparece antes como a resultante de escolhas e de compromissos, de dinâmicas identificáveis, e de resistências laterais que impactam o movimento do conjunto (Ibid).

A noção de transição dialoga com a ideia de paradigma. A mudança é uma troca de paradigmas. Como expõe Roberto Crema, paradigma refere-se a modelo, padrão e exemplos compartilhados, significando um esquema modelar para a descrição, explicação e compreensão da realidade(CREMA, 1989, p. 18). O autor salienta que a mudança de paradigma não é um processo simples, em que pese a ciência propicie, com sua dinâmica, o caminho para uma automudança. A transição para uma nova estrutura conceitual geralmente é 
procedida de um grande stress, bem como de uma forte resistência daqueles que se situam no paradigma em crise. O fenômeno da conversão ao novo paradigma, que é sempre uma transição entre incomensuráveis, encontra-se no próprio cerne do processo revolucionário que conduz a uma nova tradição científica(Ibid., p. 20).

A transição agroecológica deve ser situada neste debate. Ela não constitui apenas uma simples reforma pontual nas técnicas de produção agrícola, mas uma mudança estrutural que inclui uma nova relação entre o agricultor e o meio ambiente. A transição que se busca apontar neste momento relaciona-se com a identificação de um modelo agrícola que respeite os princípios socioambientais. Este modelo será denominado no curso deste trabalho de agroecológico/agroecologia, em que pese se reconheça denominações similares sem grandes alterações de significado, como agricultura ecológica, agricultura orgânica ou agricultura verde. De acordo com Miguel Altieri

\begin{abstract}
A agroecologia fornece uma estrutura metodológica de trabalho para a compreensão mais profunda tanto da natureza dos agroecossistemas como dos princípios segundo os quais eles funcionam. Trata-se de uma nova abordagem que integra os princípios agronômicos, ecológicos e socioeconômicos à compreensão e avaliação do efeito das tecnologias sobre os sistemas agrícolas e a sociedade como um todo. Ela utiliza os agroecossistemas como unidade de estudo, ultrapassando a visão unidimensional - genética, agronomia, edafologia - incluindo dimensões ecológicas, sociais e culturais (ALTIERI, 2004, p. 23).
\end{abstract}

Neste sentido, a agroecologia não constitui apenas um conjunto de técnicas de produção, mas um plano científico que estabelece as bases para a construção de estilos de agricultura sustentável e de estratégias de desenvolvimento rural sustentável(CARPORAL, COSTABEBER, 2002, p. 71). Assim, são identificadas na noção de agroecologia ao menos seis dimensões: ecológica, social, econômica, cultural, política e ética. Cabe fazer uma breve exposição acerca de cada uma delas:

a) Dimensão ecológica: a manutenção da base de recursos naturais constitui um aspecto central para a conquista de patamares crescentes de sustentabilidade em qualquer agroecossistema. Não importa quais sejam as estratégias para a intervenção técnica $e$ planejamento do uso dos recursos (...), mas importa ter em mente a necessidade de uma 
abordagem holística e um enfoque sistêmico, dando um tratamento integral a todos os elementos do agroecossistema que venham a ser impactados pela ação humana (Ibid. p. 76).

b) Dimensão social: a preservação ambiental e a conservação dos recursos naturais somente adquirem significado e relevância na medida em que os produtos gerados nos agroecossistemas, em bases renováveis, sejam eqüitativamente apropriados e usufruídos pelos diversos segmentos da sociedade. Além do mais, a dimensão social inclui a busca contínua de melhores níveis de qualidade de vida mediante a produção e o consumo de alimentos com qualidade biológica superior(Ibid., p 77).

c) Dimensão econômica: os resultados econômicos constituem elementos importantes para o fortalecimento das estratégias de desenvolvimento rural sustentável. Contudo, a lucratividade não é o fator preponderante na lógica da agroecologia. $A$ sustentabilidade de agroecossistemas também supõe a necessidade de obter-se balanços agroenergéticos positivos, sendo necessário compatibilizar a relação entre produção agropecuária e consumo de energias não renováveis(Ibid).

d) Dimensão cultural: na perspectiva da agroecologia, torna-se necessário que as intervenções sejam respeitosas com o cenário cultural. A agricultura, nesse sentido, precisa ser entendida como atividade econômica e sociocultural - uma prática social - realizada por sujeitos que se caracterizam por uma forma particular de relacionamento com o meio ambiente(Ibid., p. 78).

e) Dimensão política: esta dimensão relaciona-se com a necessidade de práticas participativas e democráticas entre os grupos/atores envolvidos na produção agrícola e no desenvolvimento rural. Nesse contexto, o desenvolvimento rural sustentável deve ser concebido a partir das concepções culturais e políticas próprias dos grupos sociais, considerando-se suas relações de diálogo e de integração com a sociedade maior(Ibid., p. 78-79).

f) Dimensão ética: relaciona-se com a solidariedade intra e intergeracional, bem como com as novas responsabilidades dos indivíduos perante o meio ambiente. Sendo assim, a dimensão ética a que nos referimos exige pensar e fazer viável a adoção de novos valores, que não necessariamente serão homogêneos(Ibid., p. 79-80).

Nos termos da Organização das Nações Unidas para a Alimentação e a Agricultura FAO, a agroecologia é definida como 
um sistema de gestão global de produção que exclui a utilização de fertilizantes, de pesticidas e de organismos geneticamente modificados, reduzindo ao máximo a poluição do ar, do solo e da água, e otimizando a saúde e a produtividade de comunidades interdependentes de vegetais, de animais e de seres humanos (FAO, 2007 - tradução do autor).

A concepção introduzida pela FAO parece ter sido tímida ao não incluir elementos da dimensão cultural, ética e econômica. Como dito, a mera alteração de técnicas de produção (com a exclusão do uso de inseticidas, por exemplo) e a preocupação com a saúde dos envolvidos não é suficiente para a mudança paradigmática antes referida.

A legislação brasileira (lei 10.831/2003) adotou o conceito de sistemas orgânicos de produção agropecuária para definir o método de produção onde são adotadas

técnicas específicas, mediante a otimização do uso dos recursos naturais e socioeconômicos disponíveis e o respeito à integridade cultural das comunidades rurais, tendo por objetivo a sustentabilidade econômica e ecológica, a maximização dos benefícios sociais, a minimização da dependência de energia não-renovável, empregando, sempre que possível, métodos culturais, biológicos e mecânicos, em contraposição ao uso de materiais sintéticos, a eliminação do uso de organismos geneticamente modificados e radiações ionizantes, em qualquer fase do processo de produção, processamento, armazenamento, distribuição e comercialização, e a proteção do meio ambiente (art. $1^{\circ}$, caput) ${ }^{4}$.

Dentre as finalidades estabelecidas na lei para estes sistemas de produção, salienta-se a oferta de produtos saudáveis isentos de contaminantes intencionais; a preservação da diversidade biológica dos ecossistemas naturais e a recomposição ou incremento da diversidade biológica dos ecossistemas modificados; o incremento da atividade biológica do solo; a promoção do uso saudável do solo, da água e do ar, e a redução ao mínimo de todas as formas de contaminação desses elementos que possam resultar das práticas agrícolas; a

\footnotetext{
${ }^{4}$ No âmbito administrativo, contudo, o Ministério da Agricultura, Pecuária e Estabelecimento, já aportava conceito semelhante. Segundo a Instrução Normativa $n^{\circ}$, de 17 de maio de 1999 , o sistema orgânico de produção agropecuária e industrial é todo aquele em que se adotam tecnologias que otimizem o uso de recursos naturais e socioeconômicos, respeitando a integridade cultural e tendo por objetivo a auto sustentação no tempo e no espaço, a maximização dos benefícios sociais, a minimização da dependência de energias não renováveis e a eliminação do emprego de agrotóxicos e outros insumos artificiais tóxicos, organismos geneticamente modificados - (OGM)/transgênicos, ou radiações ionizantes em qualquer fase do processo de produção, armazenamento e de consumo, e entre os mesmos, privilegiando a preservação da saúde ambiental e humana, assegurando a transparência em todos os estágios da produção e da transformação.
} 
manutenção ou incremento da fertilidade do solo a longo prazo; a reciclagem de resíduos de origem orgânica, reduzindo ao mínimo o emprego de recursos não-renováveis; a organização da produção baseada em recursos renováveis e em sistemas agrícolas organizados localmente; o incentivo da integração entre os diferentes segmentos da cadeia produtiva e de consumo de produtos orgânicos, além da regionalização da produção e comércio desses produtos; e, finalmente, a manipulação dos produtos agrícolas com base no uso de métodos de elaboração cuidadosos, com o propósito de manter a integridade orgânica e as qualidades vitais do produto em todas as etapas $\left(\operatorname{art} .1^{\circ}, \S 1^{\circ}\right)$.

Feita essa análise conceitual, cabe investigar como os programas de pagamento por serviços ambientais podem dialogar com os objetivos da transição agroecológica, o que é feito no capítulo seguinte.

\section{As estratégias PSA direcionados à agricultura: um estudo sobre as experiências européia e brasileira.}

A utilização de mecanismos financeiros como catalisador de práticas agrícolas sustentáveis ainda aguarda um aporte científico no contexto brasileiro. Vencido o desafio conceitual proposto na primeira etapa desse trabalho, o artigo apresenta uma análise comparada entre a experiência européia e as recentes iniciativas verificadas no âmbito político brasileiro. A primeira é caracterizada por uma consolidada integração de mecanismos de pagamento na política agrícola, através da noção de condicionalidade (2.1). A sistemática brasileira, em que pese alguns avanços meritórios, ainda carece de instrumentos econômicojurídicos estimuladores de uma transição agroecológica (2.2).

\subsection{O pagamento por serviços ambientais na Política Agrícola Comum Europeia (PAC): a noção de condicionalidade}

A Política Agrícola Comum - PAC constituiu a estratégia europeia para os problemas de produção e distribuição de alimentos no póssegunda guerra, momento no qual a Comunidade Econômica Europeia era deficitária para a maior parte dos produtos. Em que pese a Política Agrícola Europeia - PAC tenha sido formalmente criada apenas em 1962, já na redação do Tratado de Roma instituidor da Comunidade Econômica Europeia em 1957, havia a previsão de sua formatação. Nos termos do artigo 39 do Tratado, a PAC tinha por 
objetivo (a) incrementar a produtividade da agricultura, fomentando o progresso técnico, assegurando o desenvolvimento racional da produção agrícola e a utilização ótima dos fatores de produção, designadamente da mão-de-obra; (b) assegurar um nível de vida equitativo à população agrícola, designadamente pelo aumento do rendimento individual dos que trabalham na agricultura; (c) estabilizar os mercados; (d) garantir a segurança dos abastecimentos e; (e) assegurar preços razoáveis nos fornecimentos aos consumidores.

Paulatinamente, os objetivos da Política Agrícola Comum incorporaram preocupações ambientais. Em 1985, a Comissão Europeia apresenta o livro verde sobre o futuro da PAC, salientando a importância da agricultura para a preservação do meio ambiente rural, e não apenas suas funções econômicas e sociais. O relatório reconheceu que o desenvolvimento de modernas técnicas agrícolas teve um papel importante para o incremento da agricultura. Contudo, ele foi também diretamente responsável pela extinção de espécies da flora e da fauna, além da destruição de ecossistemas valiosos. Nesta linha, o relatório propôs a adoção de práticas amigáveis ao meio ambiente, como a adoção de políticas designadas para a promoção de práticas que conservem o ambiente rural e áreas específicas de proteção (COMMISSION OF THE EUROPEAN COMMUNITIES, 1985, p. 51).

Essa tendência foi observada durante os debates da reforma da PAC denominada Agenda 2000 (consolidada em Berlim no ano de 1999). Além das fortes reduções nos subsídios dos cereais, a Agenda 2000 foi marcada pela integração de objetivos ambientais na PAC. Assim, conforme se observa no documento Agenda 2000: para uma União reforçada e alargada, publicada ainda em 1997, as ações da política comum passariam a conferir

uma importância acrescida aos instrumentos agroambientais destinados a apoiar o desenvolvimento duradouro das zonas rurais e a responder ao aumento crescente das exigências da sociedade em matéria de serviços ecológicos. Todas as medidas destinadas a manter e a reforçar a qualidade do ambiente devem ser reforçadas e desenvolvidas.

Para melhor integrar o ambiente nas organizações comuns de mercado, a Comissão apresentará uma proposta que autorizará os Estados-Membros a efetuar pagamentos diretos, sob reserva do respeito das disposições ambientais (COMISSÃO EUROPEIA, 1997, p. 35). 
Neste sentido, a criação de um segundo pilar para a PAC constituiu a grande novidade da Agenda 2000, identificada no estabelecimento de uma política de desenvolvimento rural. Tal inovação pode ser dividida em três vias. A primeira, de cunho econômico e social, refere-se à instalação dos jovens na agricultura, à modernização da produção, à transformação e comercialização dos produtos, bem como ao apoio à silvicultura. A segunda via concerne justamente às medidas agroambientais que os Estados-membros são autorizados a adotar, as quais são complementadas, finalmente, pela terceira via, que diz respeito ao desenvolvimento das zonas rurais(BOURGET, 2011, p. 34).

Uma nova reforma da Política Agrícola Comum é observada em 2003. Tais modificações visavam reforçar a integração comercial da União Europeia ao comércio internacional, adaptando as práticas de subsídio dos agricultores às imposições da Organização Mundial do Comércio, além de dar resposta à crescente demanda por práticas agrícolas sustentáveis. Dentre as diversas inovações, destaca-se a noção de condicionalidade (“cross-compliance"), que subordinou os pagamentos únicos ao respeito de uma série de critérios em matéria de ambiente e de saúde pública.

A ideia de condicionalidade é fundamental para a compreensão do sistema de pagamento por serviços ambientais no âmbito da Política Agrícola Comum. Nos termos do artigo $3^{\circ}$ do regulamento $1.782 / 2003^{5}$, qualquer agricultor que se beneficie de pagamentos diretos deve respeitar os requisitos legais de gestão estabelecidos, assim como as boas condições agrícolas e ambientais definidas nos termos do artigo $5^{\circ}$. Este artigo, por sua vez, estabelece que os parâmetros e requisitos mínimos para as boas condições agrícolas e ambientais devem ser definidas pelos estados-membros, levando-se em consideração as características específicas das zonas em questão, nomeadamente as condições edafoclimáticas, os sistemas de exploração, a utilização das terras, a rotação das culturas, as práticas agrícolas, assim como as estruturas agrícolas existentes.

Este princípio é reforçado em 2005, a partir de quando todos os agricultores que recebem pagamentos diretos são submissos à condicionalidade, organizada em dois eixos. O primeiro refere-se às exigências regulamentares em matéria de gestão, meio ambiente, segurança alimentar, saúde animal e vegetal e bem-estar de animais. O segundo eixo refere-se às exigências regulamentares em matéria de boas condições agrícolas e ambientais, as quais incluem um conjunto de normas concernentes à proteção do solo (compreendendo a

\footnotetext{
${ }^{5}$ Revogado pelo Regulamento 73/2009, o qual, contudo, não alterou significativamente o conceito aqui exposto.
} 
manutenção de sua matéria orgânica e de sua estrutura), a gestão da água e as medidas visando à prevenção da deterioração dos habitats (COMMISSION EUROPÉENNE, 2016).

Saliente-se, outrossim, o modelo de desenvolvimento reafirmado pela PAC. Denominado de iniciativa LEADER - relações entre ações de desenvolvimento rural (expressão original em língua francesa: Liaison entre actions de développement rural), o modelo, lançado em 1991, constitui um método de mobilizar e incentivar o desenvolvimento nas comunidades rurais locais e não apenas um conjunto de medidas a serem efetivadas. Ela tem por base iniciativas e competências locais, promovendo a aquisição do saber-fazer no domínio do desenvolvimento integrado local e divulgando esse saber-fazer a outras zonas rurais (COMISSÃO EUROPEIA, 2006, p. 5-6).

Desde o seu lançamento em 1991 que a abordagem Leader proporcionou às comunidades rurais da UE as ferramentas necessárias para desempenharem um papel activo na definição do seu próprio futuro, tendo evoluído no tempo, simultaneamente com o resto da PAC. As informações obtidas através de avaliações e directamente dos agentes do mundo rural indicam que a abordagem Leader é um instrumento que funciona de modo adequado em situações e tipos de zonas muito diferentes, adaptando a elaboração de políticas rurais à extrema diversidade das necessidades das zonas correspondentes. Por essas razões, tornou-se uma parte integrante da política de desenvolvimento rural (Ibid., p. 5).

A iniciativa Leader é introduzida como uma iniciativa de natureza comunitária, desenvolvida inicialmente em três etapas: a iniciativa Leader I (entre 1991 e 1993), Leader II (entre 1994 e 1999) e, finalmente, Leader + (entre os anos 2000 e 2006). Em 2007 a iniciativa é incorporada à política de desenvolvimento rural da União Europeia (Ibid., p. 6). Ela abandona, assim, seu caráter regional, transitório e mesmo experimental. A importância da iniciativa Leader para o desenvolvimento rural no continente europeu foi reconhecida nos considerandos do regulamento 1.698/2005, o qual expressamente dispôs que

50. a iniciativa Leader atingiu um nível de maturidade que permite às zonas rurais executar a abordagem Leader no quadro mais vasto da programação geral relativa ao desenvolvimento rural. Por conseguinte, devem ser adotadas disposições relativas à transferência dos princípios básicos da abordagem Leader para os programas que integrem um eixo específico e à definição dos grupos de acção local e das medidas 
a apoiar, incluindo a capacidade de parceria, a execução de estratégias locais, a cooperação, a ligação em rede e a aquisição de competências.

No cenário brasileiro, não se percebe uma metodologia sofisticada de apoio à transição agroecológica. Os mecanismos já consolidados em âmbito nacional limitam-se, em grande parte, à rotulagem dos produtos orgânicos, não havendo, portanto, uma engrenagem econômica paralela.

\subsection{As estratégias nacionais de incremento da transição agroecológica}

Como dito anteriormente, foi a lei 10.831 que incorporou a noção de agroecologia, através do conceito de sistemas orgânicos de produção agropecuária. A referida lei, contudo, somente foi regulamentada no ano de 2007, através do decreto 6.323, que instituiu o Sistema Brasileiro de Avaliação da Conformidade Orgânica. O decreto estabeleceu os procedimentos para a certificação da agricultura orgânica, definida como o ato pelo qual um organismo de avaliação da conformidade credenciado dá garantia por escrito de que uma produção ou um processo claramente identificado foi metodicamente avaliado e está em conformidade com as normas de produção orgânicas vigentes.

Nos termos do decreto, o processo de certificação orgânica, que resulta finalmente na inclusão do produtor no Cadastro Nacional de Produtores Orgânicos, deve respeitar a tradição, a cultura e os mecanismos de organização social nas relações de trabalho em condições especiais das comunidades locais tradicionais. O Cadastro Nacional de Produtores Orgânicos, segundo dados do Ministério da Agricultura, Pecuária e Abastecimento de agosto de 2015 , contava com 11.207 cadastros $^{6}$. O número era de 10.505 cadastros em maio de 20157 . Em janeiro de 2014, segundo dados do MAPA, este número era de apenas 6.719 produtores, o que representa um crescimento de praticamente $100 \%$ num período de 19 meses. É importante salientar que este crescimento não é proveniente unicamente da política de transição agroecológica em curso, mas também da regularização de agricultores que já praticavam esta modalidade de produção, porém não haviam ainda obtido a certificação.

\footnotetext{
${ }^{6} \mathrm{~A}$ listagem dos produtores, bem como das respectiva entidade certificadora, estão disponibilizados no site www.agricultura.gov.br/desenvolvimento-sustentavel/organicos/cadastro-nacional. Acesso em 25 de agosto de 2015.

${ }^{7} \mathrm{O}$ cadastro disponibilizado pelo MAPA informa o número de unidades controladas. Contudo, não necessariamente uma unidade controlada corresponde a uma unidade produtiva. Isso se deve ao fato de, algumas vezes, a unidade detendora da certificação ser uma associação ou cooperativa de produtores orgânicos. Portanto, os números do MAPA podem estar subestimados.
} 
Em 2012, através do decreto 7.794, de 20 de agosto, foi instituído a Política Nacional de Agroecologia e Produção Orgânica (PNAPO), com o objetivo de integrar, articular e adequar políticas, programas e ações indutoras da transição agroecológica e da produção orgânica e de base agroecológica. O decreto apresenta um conceito de transição ecológica para o direito brasileiro, qual seja,

o processo gradual de mudança de práticas e de manejo de agroecossistemas tradicionais ou convencionais por meio da transformação das bases produtivas e sociais do uso da terra e dos recursos naturais, que levem a sistemas de agricultura que incorporem princípios e tecnologias de base ecológica.

Dentre as diretrizes da Política Nacional de Agroecologia e Produção Orgânica cabe salientar justamente a prioridade do apoio institucional à agricultura familiar no objetivo de promover sistemas justos e sustentáveis de produção, que aperfeiçoem as funções econômica, social e ambiental da agricultura e do extrativismo florestal.

Dentre os mecanismos da PNAPO podem ser destacados uma série de instrumentos econômicos, tais como o crédito rural e de outras formas de financiamento (art. 4, II); o seguro agrícola e de renda (art. $4^{\circ}$, III); a regulação, compensação e subvenção de preços agrícolas e extrativistas (art. $\left.4^{\circ}, \mathrm{IV}\right)$; as compras governamentais (art. $4^{\circ}, \mathrm{V}$ ); além de medidas fiscais e tributárias (art. $\left.4^{\circ}, \mathrm{VI}\right)$.

A Política Nacional ainda determinou a elaboração de um Plano Nacional de Agroecologia e Produção Orgânica (PLANAPO), com o objetivo de diagnosticar a situação da agricultura orgânica no país, bem como estabelecer estratégias, programas, ações, metas e prazos (BRASIL, 2013). O PLANAPO foi elaborado em 2013 (com ações previstas até 2015)e incorporou como desafios, dentre outros aspectos, a ampliação do número de agricultores envolvidos com a produção orgânica; o fomento à conservação, ao manejo e ao uso sustentável dos recursos naturais; e a democratização do conhecimento agroecológico (Ibid., p. 16). Para tanto, o Plano reconhece que a transição ecológica e a conversão para sistemas orgânicos de produção requerem o estabelecimento de um processo capaz de implementar mudanças multilineares e graduais nas formas de (re)desenho e manejo dos agrossistemas, envolvendo custos de transição(Ibid.).

As medidas planejadas encontram-se em fase de desenvolvimento, de modo que não existem neste momento estudos e relatórios de avaliação do PLANAPO. Contudo, cabe 
salientar o tamanho do desafio do país, e também seu potencial, no que se refere à transição agroecológica. Para tanto, cabe apresentar um breve quadro do cenário internacional.

Segundo dados da Federação Internacional de Movimentos de Agricultura Orgânica (IFOAM) e do Instituto de Pesquisa de Agricultura Orgânica (FiBL) de 2014 (IFOAM, FiBL, 2014), o Brasil ocupa apenas a décima posição mundial em áreas dedicadas à agricultura orgânica, com cerca de 705 mil hectares. Levando-se em consideração a área agricultável informada pelo Instituto Brasileiro de Geografia e Estatística (IBGE) no Censo Agropecuário de 2006 (IBGE, 2006, p. 26), qual seja, de 329.941.393 hectares, o Brasil destina apenas $0,21 \%$ para a agricultura orgânica.

Os dados da IFOAM apontam para um cenário ainda tímido da agricultura orgânica do Brasil quando comparado também com os demais países do Mercosul. A Argentina apresenta 2,59\% de seu território agrícola direcionado à agricultura orgânica, ocupando cerca de 3,6 milhões de hectares. O Uruguai possui 6,29\% das suas áreas cultivadas com agricultura orgânica, em torno de 930.965 hectares.

Ao contrário do contexto europeu, o Brasil ainda não possui qualquer instrumento econômico de incentivo à transição agroecológica. O novo Código Florestal (lei 12651/2012) apresentou, em seu artigo 41, a autorização para a adoção de uma política nacional de serviços ambientais, destinada, à promoção da valorização cultural e do conhecimento tradicional ecossistêmico e a conservação e o melhoramento do solo (dentre outros serviços relacionados à produção agroecológica). Contudo, a regulamentação dos programas, sobretudo no que se refere à origem dos recursos e à operacionalização prática, ainda carece de articulação normativa e política.

\section{CONCLUSÃO}

Os Programas de Pagamento por Serviços Ambientais tem constituído uma das inovações mais promissoras no âmbito do direito ambiental brasileiro. As inúmeras experiências regionais observadas principalmente com os fins de preservação e recuperação de matas ciliares e florestas tem recebido críticas positivas no espaço acadêmico. O novo Código Florestal, em seu artigo 41, inovou em positivar a possibilidade de instituição de um programa de base nacional, promovendo, além dos serviços ambientais mais destacados pela doutrina (como o seqüestro de carbono), aqueles fornecidos diretamente pela atividade 
agrícola, como a conservação da biodiversidade, a valorização cultural e do conhecimento tradicional ecossistêmico, a conservação e o melhoramento do solo, etc.

No cenário agrícola brasileiro, caracterizado por práticas produtivas pouco sustentáveis, as estratégias para a mudança das bases produtivas no meio rural têm alcançado resultados ainda tímidos. Nessa linha, a análise da Política Agrícola Comum - PAC na Europa fornece elementos importantes para o contexto brasileiro. Caracterizado por uma preocupação inicial de crescimento produtivo e organização da distribuição de alimentos, a PAC paulatinamente absorveu princípios socioambientais. Os mecanismos de pagamentos diretos aos agricultores incorporaram a noção de condicionalidade, traduzida num efetivo programa de pagamento por serviços ambientais.

No cenário brasileiro, as políticas de transição agroecológica e de incentivo à adoção de práticas ambientalmente sustentáveis ainda se limitam a rotulagem e à criação de um banco de dados de alcance nacional. Contudo, percebe-se a carência de mecanismos jurídicos econômicos que possam alavancar a produção orgânica. Evidentemente, a importação do sistema europeu para a realidade brasileira exige a observância criteriosa das diferenças sociais, políticas, agrárias e, sobretudo, econômicas que existem entre os diferentes contextos. Contudo, a análise comparada indica que os programas PSA possuem potencial para estimular uma transição agroecológica profunda na perspectiva brasileira.

\section{REFERÊNCIAS BIBLIOGRÁFICAS}

ABDELMALKI, Lahsen; MUNDLER, Patrick. Economie de L'environnement et du Développement Durable. Éditions de Boeck: Bruxelles, 2010.

ALtMANN, Alexandre; BUTZKE, Alindo. Pagamento por Serviços Ambientais como Promotor da Agroecologia e da Segurança Alimentar. In :Florestas, Mudanças Climáticas e Serviços Ecológicos (organizado por Antônio Herman Benjamin, Carlos Teodoro Irigaray, ElodioLecey e Silvia Cappeti). São Paulo : Imprensa Oficial do Estado de São Paulo, 2010.

ALTIERI, Miguel. Agroecologia: a dinâmica produtiva da agricultura sustentável. Traduzido por Marília Marques Lopes. 4.ed. Porto Alegre: Editora da UFRGS, 2004. Disponível em https://www.socla.co/wp-content/uploads/2014/Agroecologia-Altieri-Portugues.pdf. 
ARAGÃO, Alexandra. O Princípio do Poluidor Pagador. Pedra Angular da Política Comunitária do Ambiente. São Paulo: Instituto o Direito por um Planeta Verde, 2014.

ASSOCIAÇÃO BRASILEIRA DE SAÚDE COLETIVA - ABRASCO. Dossiê Abrasco. Um alerta sobre os impactos dos agrotóxicos na Saúde. Organizado por Fernando Ferreira Carneiro, Lia Giraldo da Silva Augusto, Raquel Maria Rigotto, Karen Friedrich e André Campos Búrigo. Rio de Janeiro: EPSJV; São Paulo: Expressão Popular, 2015.

BENJAMIN, Antônio Herman; IRIGARAY, Carlos Teodoro; LECEY, Elodio; CAPPETI, Silvia (organizadores). Florestas, Mudanças Climáticas e Serviços Ecológicos. São Paulo: Imprensa Oficial do Estado de São Paulo, 2010.

BOURGET, Bernard. Les Défis de L'Europe Verte : essai sur la politique agricole commune. Paris :L’Harmattan, 2011.

BRASIL. Câmara Interministerial de Agroecologia e Produção Orgânica. Plano Nacional de Agroecologia e Produção Orgânica - PLANAPO. Brasília, DF: MDS; CIAPO, 2013.

CARPORAL, Francisco Roberto; COSTABEBER, José Antônio. Análise Multidimensional da Sustentabilidade. Uma proposta metodológica a partir da Agroecologia. Agroecologia e Desenvolvimento Rural Sustentável, Porto Alegre, v.3, n.3, Jul/Set 2002.

CHABOT, Pascal. L’Âge des Transitions. Paris: PUF, 2015.

COMISSÃO EUROPEIA. Boletim da União Europeia. Suplemento 5/97. Agenda 2000: para uma União reforçada e alargada. Luxemburgo: Serviço das Publicações Oficiais das Comunidades Europeias, 1997.

COMISSÃO EUROPEIA. A Abordagem Leader. Um guia básico. Luxemburgo: Serviço das Publicações Ofi ciais das Comunidades Europeias, 2006.

COMMISSION OF THE EUROPEAN COMMUNITIES. Perspectives for the common agricultural policy. Brussels , 15 july 1985, p. 51 Available in http://ec.europa.eu/greenpapers/pdf/green_paper_perspectives_for_cap_com_85_333.pdf. Accessed on 28/02/2016. 
COMMISSION EUROPÉENNE, 2016. Página de divulgação das estratégias de agricultura e desenvolvimento rural. http://ec.europa.eu/agriculture/envir/cross-compliance/index_fr.htm. Acesso em 20/09/2016.

CREMA, Roberto. Introdução à Visão Holística. Breve relato de viagem do velho ao novo paradigma. São Paulo: Summus, 1989.

DELORME, Hélène. Introduction. La politique agricole commune. Anatomie d'une transformation (sous la direction de Hélène Delorme). Paris :Presses de SciencesPo, 2004.

FURLAN, Melissa. Mudanças Climáticas e Valoração Econômica da Preservação Ambiental: o pagamento por serviços ambientais e o princípio do protetor-recebedor.Curitiba: Juruà, 2010.

HUPFFER, Haide Maria; FIGUEIREDO, João Alcione Sganderia; TANDISI, José Galizia (organizadores). Pagamento por serviços ambientais. Incentivos econômicos para a proteção dos recursos hídricos e restauração da mata ciliar. Porto Alegre: Entremeios, 2013.

IRIGARAY, Carlos Teodoro José Hugueney. Pagamento por Serviços Ecológicos e o Emprego de REDD na Amazônia. In: Direito e Mudanças Climáticas: serviços ecológicos (organizado por Paula Lavratti e VanescaBuzelato Prestes). São Paulo: Instituto o Direito por um Planeta Verde, 2010.

INTERNATIONAL FEDERATION OF ORGANIC AGRICULTURE MOVEMENTS - IFOAM. RESEARCH INSTITUTE OF ORGANIC AGRICULTURE (FiBL). The World of Organic Agriculture. Statistics \& Emerging Trends 2014. 2014. Disponível em www.fibl.org/fileadmin/documents/shop/1636-organic-world-2014.pdf. Acesso em 03/08/2015.

INSTITUTO BRASILEIRO DE GEOGRAFIA E ESTATÍSTICA. Censo Agropecuário 2006. Agricultura Familiar. Primeiros Resultados. Brasil, Grande Regiões e Unidades da Federação. Rio de Janeiro : IBGE, 2006.

LANGLAIS, Alexandra. Les paiements pour services environnementaux, une nouvelle forme d'équité environnementale pour les agriculteurs ? Reflexions juridiques. Revue de Droit Rural. № 413, mai 2013, étude 7 
MEIRELLES, Dimária Silva. Teorias de mercado e regulação: por que os mercados e o governo falham? Cadernos EBAPE.BR, v. 8, n ${ }^{4}$, artigo 5, Rio de Janeiro, dez. 2010.

MORATO LEITE, José Rubens; PILATI, Luciana Cardoso. Reparabilidade do dano ambiental no sistema da responsabilização civil: 25 anos da lei 6938/1981. Revista Sequência, n ${ }^{\circ}$ 53, dez. 2006.

ORGANIZATION DES NATIONS UNIES POUR L'ALIMENTATION ET L'AGRICULTURE. Site de la Conférence internationale sur l'agriculture biologique et la sécurité alimentaire - Rome, 03 - 05 mai 2007. Disponible à http://www.fao.org/organicag/ofs/index_fr.htm. Acess à 17/01/2016

OST, François. A natureza à margem da lei. A ecologia à prova do direito.Lisboa; Instituto Piaget, 1995.

SERVICE INTERNATIONAL POUR L'ACQUISITION DES APPLICATIONS D'AGROBIOTECHNOLOGIE. Résumé. Rapport $n{ }^{\circ}$ 46. État mondial des cultures transgéniques commercialisées: 2013.

SEEHUSEN, Susan Edda; PREM, Ingrid. Por que Pagamento por Serviços Ambientais? In. Pagamento por Serviços Ambientais na Mata Atlântica: lições aprendidas e desafios. (organizado por Fátima Becker Guedes e Susan EddaSeehusen). Brasília: MMA, 2011.

WUNDER, Sven. Payments for environmental services: some nuts and bolts.CIFOR OccasionalPaper $n^{\circ}$ 42, 2005.z 